Vol. 108, Pt 3, June 1987 JASIAB 108 (Pt 3) 515-707 (1987) ISSN 0021-8596

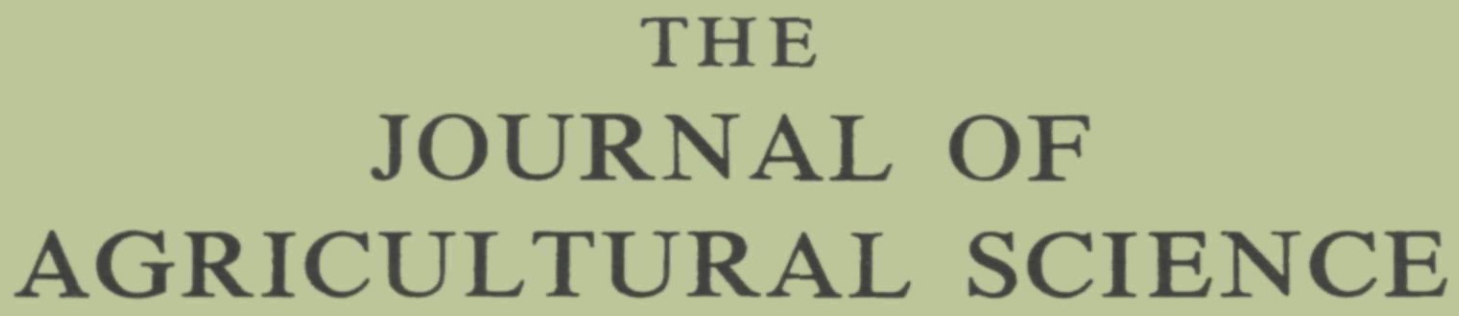

EDITED BY

R. B. A USTIN, D.SC., Plant Breeding Institute, Cambridge

B. W. BACHE, M.A., PH.D., C.CHEM., F.R.S.C., Department of Applied Biology, Cambridge

Prof. Sir J. W. L. BEAMENT, SC.D., F.R.S., Department of Applied Biology, Cambridge

G. D. H. BELL, C.B.E., PH.D., SC.D. (h.c.), D.SC. (h.c.), F.R.S., 6 Worts Causeway, Cambridge Sir K. L. BLAXTER, PH.D., N.D.A. (HONS.), D.SC., F.R.S.E., F.R.S., Stradbroke Hall, Stradbroke, Suffolk

Prof. A. D. CA R E, D.SC., M.R.C.V.s., Department of Animal Physiology and Nutrition, Leeds J. A. CUR RIE, PH.D., 6 Falconers Field, Harpenden

W. DAY, PH.D., Rothamsted Experimental Station, Harpenden

S. K. ELTRINGHAM, PH.D., Department of Applied Biology, Cambridge

Prof. J. L. JINK S, C.B.E., D.SC., F.I.BIOL., F.R.S., Agricultural and Food Research Council, 160 Great Portland Street, London, W1N 6DT

D. B. LINDSA Y, B.SC., M.A., D.PHIL., CSIRO Division of Tropical Animal Science, Tropical Cattle Research Centre, Rockhampton, Queensland, Australia

Prof. G. M. O. MA LOIY, E.B.S., PH.D., D.SC., D.SC. (h.c.), F.I.BIOL., College of Agriculture and Veterinary Sciences, University of Nairobi, Kenya

Prof. J. B. OWEN, B.SC., PH.D., M.A., Department of Agriculture, Bangor

W. J. RIDGMAN, M.A., Department of Applied Biology, Cambridge

D. E. WALTERS, B.SC., PH.D., F.I.S., Cambridge Research Station (IAPGR), Babraham Hall, Cambridge

F. Y A TES, C.B.E., SC.D., F.R.S., Rothamsted Experimental Station, Harpenden

Miss C. H. NORTHEAST, M.A., (Executive Editor), Department of Applied Biology, Cambridge

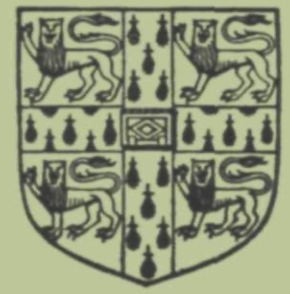

CAMBRIDGE UNIVERSITY PRESS

THE PITT BUILDING, TRUMPINGTON STREET, CAMBRIDGE CB 2 IRP

32 EAST 57TH STREET, NEW YORK, NY IOO22, USA

IO STAMFORD ROAD, OAKLEIGH, MELBOURNE 3I66, AUSTRALIA 


\section{INSTRUCTIONS TO AUTHORS}

\section{Failure to comply with the Instructions to Authors may delay publication}

The Journal welcomes concise papers reporting original experimental data or experimental methods, or new analyses of already existing data, in any aspect of Agricultural Science. It does not normally publish review articles. The Editors must be informed if any of the material submitted has been published elsewhere. If a paper is accepted, it must not be published elsewhere in the same form. Experiments on animals must conform with legislation in the country where the experiments are carried out. Papers should be submitted to Miss C. H. Northeast, Journal of Agricultural Science, Department of Applied Biology, Pembroke Street, Cambridge CB2 3DX, or to one of the Associate Editors.

SCRIPTs. Papers, written in English, should be typed in double spacing on one side of the paper with a margin of at least $4 \mathrm{~cm}$ on the left-hand side. Two copies should be submitted.

Layout and Style. Authors are recommended to use the style adopted in recent issues. Details and sample pages showing preferred layout for various subjects may be obtained in advance of submission from the Executive Editor, Miss C. H. Northeast, at the address given above.

TITLE. The title must be specific and suitable for indexing by the automatic methods now being employed. Male authors should give surnames and full initials, female authors should give one forename. The full name and address of the institution where the research was done should be stated. Change of address may be given as a footnote. A short title, not exceeding 50 characters, should be provided for the running headlines.

A SUMMARY, placed at the beginning of the text, should briefly indicate the experiments described, the main results and important conclusions.

THE TEXT. The Editors do not insist on a rigid format but it is usually convenient to divide the paper into sections, e.g. Introduction, Materials and Methods, Results, and Discussion. An excess of headings and subheadings should be avoided. The Introduction should show why the work was carried out; a detailed review of literature is not necessary. Relevant details should be given of the experimental materials and design, and the techniques and statistical methods used. Numerical results should be shown in Tables and not repeated in the text. Metric units should be used. Experimental details and Results should be recorded in the past tense. The Discussion should relate the author's results to other work on the subject and give the author's conclusions. A simple direct style of writing, avoiding unnecessary repetition and circumlocution, is preferred. Footnotes should not be used.

TABLES must be self-explanatory, typed on separate sheets, numbered consecutively and carry an appropriate title. Numerical results should be displayed as means with their relevant standard errors. Normally a mean should be rounded to one tenth of its standard error and the standard error given to one place of decimals more than the mean.

FIGURES should be.restricted to the display of results when a large number of values can be comprehended more easily; Tables and Figures may not reproduce the same data. Line drawings should be $25 \mathrm{~cm}$ wide and drawn in black waterproof ink on Bristol Board, graph paper with blue lines or tracing paper. Numbering and lettering, which must be kept to an absolute minimum, should be legibly inserted in soft pencil. A photocopy of the line drawing should be provided; a full legend describing the Figure and giving a key to all the symbols on it should be typed on a separate sheet.

PLA TES may be accepted, but only if they make a definite contribution to the value of the paper. They should be good quality, unmounted, glossy prints and be lightly numbered in pencil on the reverse side. If several plates or coloured photographs are submitted the author may be asked to contribute to the cost of reproducing them.

REFERENCES. In the text a reference should be quoted by the author's name and date (in parentheses). Where there are three authors, all names should appear at the first mention; thereafter, and at all times if there are four or more authors, the first name followed by et al. should be used, unless there is ambiguity, in which case all the names should be given at each occurrence. A list of References should be given at the end of the text giving, in alphabetical order, surname of authors, initials, year of publication (in parentheses), title of paper, name of journal in full (underlined to denote italics), volume and first and last pages of the reference. Authors should check that all references in the text appear at the end of the paper and vice versa, and that names and dates correspond in the two places.

SHORT NOTES may be accepted provided they are based on adequate experimental evidence; special provision is made for their publication with the least possible delay. MSS should not exceed 1500 words in length or their equivalent (a SUMMARY is not required). For tabulated matter allow 25 words per line of the table (including headings). For line illustrations allow 225 words per quarter of page.

Proofs will be sent to authors to enable them to check the correctness of the type-setting. Excessive alterations due to amendments of the author's original agreed copy may be charged to the author.

OFFPRINTS. Contributors will receive 25 copies of their papers free and can order others when they receive the proofs.

SU BSCRIPTIONS. The Journal of Agricultural Science is published annually in two volumes of three parts. All orders must be accompanied by payment. The subscription price of volumes 108 and 109,1987 , is $£ 62.50$ net (USA and Canada US \$142.50) per volume (post free); single parts are available at $£ 22.50$ net (USA and Canada US \$53.00) plus postage. Orders or enquiries may be sent to any bookseller or subscription agent, or to the publisher: Cambridge University Press, The Edinburgh Building, Shaftesbury Road, Cambridge CB2 2RU (USA and Canada, Cambridge University Press, 32 East 57th Street, New York, NY 10022, USA). Second class postage paid at New York, NY, and at additional mailing offices. PostMASTER: send address changes in USA and Canada to The Journal of 